\title{
m-Voting: Understanding the complexities of its implementation
}

\author{
Noluntu Mpekoa, Darelle van Greunen \\ Nelson Mandela Metropolitan University, Port Elizabeth, South Africa
}

\begin{abstract}
The phenomenon of the use of Information Technology in the election process is hastily gaining momentum. This development referred to as e-voting offers more benefits than the paper-based voting system. The field of e-voting and especially m-voting is mostly an undiscovered domain and its true extensity is still mostly uncharted. Very few countries have successfully implemented m-voting and diminutive research has been conducted to investigate the factors and components that influence the successful implementation of m-voting in the African context. Successful m-voting implementation depends on a collection of factors, which may be unique given the local context where it is implemented. This study found it vital to interrogate the literature to investigate common factors that may influence the successful implementation of m-voting. This paper documents a systematic review of various research studies seeking to find factors for m-voting implementation and collates results from 11 studies, where 14 common factors were found. The factors discovered for m-voting implementation include: ICT infrastructure, legal and institutional factors, security and trust, acceptance and adoption of ICT, political factors, voter education, finances and many other factors. This study contributes to the body of knowledge by identifying key factors that affect the successful implementation of m-voting.
\end{abstract}

\section{Introduction}

Voting is a critical feature of any democratic process and is a vital expression of the people's power [1], [2], [3]. This citizens' democratic right must be kept confidential and follow the one-manone vote policy. Voting methods vary from traditional voting systems to electronic voting systems [2], [3], [4].

Traditional voting systems include voice vote, the use of stones/balls, the raising of the hand and also the well-known paper-based system [2], [4], [5]. South Africa makes use of the traditional paperbased voting system still today with its downfalls [1], [4], [5]. Paper-based voting system is time consuming and can result in a number of problems [2], [5], [6], [7].

New advances in Information and Communication Technology (ICT) have changed nearly every facet of our lives [8], [9], [10]. Modern societies completely rely on ICT for business, work and leisure time activities, except in the area of voting. The use of ICT for democratic decisions making is still in its infancy. The development and widespread use of ICT is changing the way communities view voting processes and, eventually, the way they vote [10], [11]. By utilizing ICT, traditional electoral procedures can be simplified to save the cost of human resources and time [1], [2], [9], [12].

Several countries have started looking into improving the traditional paper-based voting system by using Information Communication and Technology (ICT) [1], [13], [14]. Societies rely on ICT for business, work and leisure time activities [2], [13] and by using ICT, traditional electoral procedures can be simplified and reduce the cost of human resources and time [5], [8], [15]. Mobile voting (m-voting) is a subset of e-voting, which is the use of mobile devices to cast their votes via the readily available Global System for Mobile Communications (GSM) network, outside the restricted electoral boundaries [2], [5], [9]. M-voting systems have the potential to improve traditional paper-based voting procedures by providing mobility, convenience and flexibility to the voter [1], [2], [16].

The field of e-voting and especially $\mathrm{m}$-voting is mostly an undiscovered sphere and its true extensity is still mostly uncharted [1], [2], [16]. M-voting is at its infancy throughout the world, it is not in use in most parts of Africa including SA [5], [3], [4]. No empirical research till this far has been done to investigate the factors and components that influence the successful implementation of m-voting. Very few countries have endeavoured to implement m-voting and only one country Estonia [6], [14] has successfully implemented m-voting at a large scale.

A vast number of countries has either piloted or implemented e-voting (fully or partially) but very few have been successful [2], [10], [16]. Despite the numerous benefits and advantages provided by evoting, the decision to build such a system in order to conduct elections over public networks is neither simple or straight forward. The reason being that a long list of multidisciplinary requirements must be fulfilled [1], [2], [12]. Successful m-voting implementation depends on a collection of factors, which may be unique given the local context where it is implemented [16], [17], [18].

It is imperative to note that the implementation of $\mathrm{m}$-voting may be very difficult if the different procedures and techniques that aid successful mvoting implementation are not in place [11], [17], 
[18]. Gefen, Rose, Warkentin and Pavlou [11] commends that to overcome failure on IS development; one should understand the issues underlying on its implementation first. Therefore, to ensure the successful implementation of m-voting, a deeper understanding is necessary to help realise what must be carried out to achieve success and avoid failure. This includes the identification of a set of factors that may influence the successful implementation of m-voting in SA. This study aims to explore factors that are significant to the successful implementation of m-voting.

This paper is structured as follows: Section 2 presents the related literature reviewed on factors affecting m-voting implementation. Section 3 discusses the research method used for the study. Section 4 presents the findings and then followed by a discussion of the common factors that influence $\mathrm{m}$ voting implementation in Section 5. Section 6 concludes the paper and Section 7 offers recommendations and possible future research.

\section{Literature review}

Many other countries have made several attempts to replace the traditional paper-based voting system with modern voting technology [2], [7], [10]. Literature suggests that these improvements started as early as in 1892 with the introduction of the leverarch machine [1], [2], then the introduction of optical-scan machines [4] and punch card systems for voting [5], [8]. The next evolution saw the introduction of Direct Recording Electronic (DREs) [12], Telephone, Kiosk, Internet voting systems [11] and lastly the mobile voting systems [2], [16]. This section discusses the benefits of e-voting systems and e-voting experiences around the world.

\subsection{Benefits of M-voting}

M-voting is the subset of e-voting [2]; hence it has key features similar with all other e-voting systems [7]. A diminutive number of authors have written on the benefits of m-voting specifically, but quite an immense number have written on e-voting. E-voting systems do not only offer mobility [2], [3] and flexibility [9], [10] to the users but also:

- Promises an increase in participation and offers voters more options - e-voting systems offers convenience to the voter, encourages more voters to cast their votes remotely, and has great potential to stimulate higher voter turnout [2], [9].

- Reduced logistical and administrative costs - the system will reduce the materials required for printing and distributing ballots. The personnel required to assist in voting stations will also reduce. E-voting is cheaper to implement because of the existing infrastructure required for voters to be able to cast their votes $[18,19]$.

- Casting and counting votes is much faster and more accurate - with e-voting systems by default there are no invalid or unclear ballots and the automatic gathering and counting of ballots reduces the amount of time spent counting votes and delivering the results [9], [20].

- Greater accessibility for the old and disabled people - the e-voting system will also accommodate the disabled and the older citizens as they will cast their votes comfortably at their own homes [7], [13].

- Greater efficiency - e-voting will reduce paper work or administrative work usually done by electoral officials and will help increase the overall efficiency of the electoral process [8], [18].

\subsection{E-voting around the world}

India is the world's largest democracy with a community of 1.1 billion; India has a constituency of 770 million people and just like most African countries, most voters reside in poor rural areas. The country developed its own electronic voting machines (EVM) which passed the pilot study and the technology was able to solve a lot of problems associated with the traditional paper-based voting system.

Before its adoption there were pilot schemes in five states to familiarise the voters with the technology, the voters supported and felt comfortable using the system for elections. The current voting mechanism has many security problems, and it is very difficult to prove security aspects [7 [12], [23].

Nigeria attempted to use electronic data capturing machines to prepare voter register for the 2007 General Elections. Due to distrust for potential massive abuse of the system, the officials had to put the plans on hold.

In addition, the huge cost of e-voting, also the high rate of illiteracy in the country, as well as the lack of political will to remedy all these, discouraged Nigeria from deploying full e-voting systems for the 2007 Elections [3], [11]. In 2015, Nigeria conducted elections using partial electronic voting system (smart card readers). The electronic readers were utilised for accreditation of prospective voters. Although the 2015 election exercise was declared the best ever in the history of the country, it was not without challenges. One of these was the failure, in many instances, of the readers to authenticate eligible voters [13], [20].

Nigeria's democracy is the most populated and overcrowded democracy in Africa with a population of about 160 million. Independent National Electoral Commission (INEC) is the body created by the constitution to organize all government elections in Nigeria. E-voting was endorsed for Nigeria's 2007 general elections, but Nigeria attempted to use 
electronic data capturing machines first to prepare the voter register for the 2007 elections [7, 12, 13]. Due to distrust for potential massive abuse of the system, the officials had to put the plans on hold. In addition, the huge cost of E-voting, also the high rate of illiteracy in the country, as well as the lack of political will to remedy all these, discouraged Nigeria from deploying full E-voting systems for the 2007 elections. In 2015, INEC implemented electronic voter authentication [13], [14].

In this system the card reader which is a portable electronic voter authentication device is configured to read a voter card. The card reader was designed specifically for the accreditation process, authentication of eligible voters before voting. The card reader was designed and configured to read only the permanent voter cards issued by the INEC and can only work on election day.

However, the electoral commission postponed the elections by six weeks, due to the poor distribution of permanent voter cards (only 34\% delivered). During the elections there were technical problems with the biometric card readers and the election were extended for a day due to delays. The technology was introduced to prevent voter fraud [1], [12], [13].

Nigeria attempted to use electronic data capturing machines to prepare voter register for the 2007 General Elections.

Due to distrust for potential massive abuse of the system, the officials had to put the plans on hold. In addition, the huge cost of e-voting, also the high rate of illiteracy in the country, as well as the lack of political will to remedy all these, discouraged Nigeria from deploying full e-voting systems for the 2007 Elections [19]. In 2015, Nigeria conducted elections using partial electronic voting system (smart card readers). The electronic readers were utilised for accreditation of prospective voters. Although the 2015 election exercise was declared the best in the history of the country, it was not without challenges. One of these was the failure, in many instances, of the readers to authenticate eligible voters [1], [12], [13].

Geneva's experience: It all started in 1982 when the parliament passed a new law on the exercise of political rights, which allowed the testing of new voting methods in cantonal or communal matters. Since then, Geneva has introduced I-voting in a controlled environment. Starting in 2001 the system went through several trials and then between 2003 and 2005 through eight official votes [7], [9]. Internet Voting implementation has been supported by almost two third of the Geneva population. The application was tested on a representative sample of Geneva citizens and they discovered that giving people time to know the Internet voting application increased public support.

Internet voting has been offered and used in two official elections, in the first elections 43.6 percent of the votes were cast on Internet, and it has been growing from there [7]. It was also noted that an enormous number of voters over the age of sixty used Internet than the expected youth. This is a clear indication that the choice of voting methods is not linked to the age [18], [19], [22].

Estonia started investigating e-voting since 2003, by 2007 they had the world's first national Internet election [14]. The Estonian experience in deploying Internet voting is discusses in detail by the U.S Election Assistance Commission, how they have systematically addressed the legal and technical considerations required to make Internet voting a functioning voting platform, as well as the political and cultural framework that promoted this innovation. About 3.4 percent voters used remote evoting and the Estonian officials said the Internet voting system used in 2007's elections proved secure despite worries about hacker attacks, identity fraud and vote count manipulation [2], [14]. In 2011 Estonia become the first country to allow its citizens to cast their votes in the parliamentary elections using mobile phones.

Although the system was not entirely a m-voting system, here the mobile phone with the respective SIM card is used to identify and authenticate the voter. The mobile phone acts as a card and a card reader at the same time but the voter still needs a computer with Internet connection for the voting process. The traditional paper-based voting is given priority and if the voter decides to go to a polling station during advance polls and cast a vote, the evote will be deleted. The elections were successful and the Estonians claim the system is the most secure way to authenticate digital signatures. Estonians are looking forward to the next elections as new improvements will be made to the current system [6], [14].

Table 1. E-voting systems implemented around the world

\begin{tabular}{|l|c|c|c|c|l|}
\hline \multicolumn{1}{|c|}{ Country } & $\begin{array}{c}\text { Voting } \\
\text { Population }\end{array}$ & $\begin{array}{c}\text { Election } \\
\text { type }\end{array}$ & $\begin{array}{c}\text { Year } \\
\text { introduced }\end{array}$ & $\begin{array}{c}\text { No of } \\
\text { elections } \\
\text { in use }\end{array}$ & Problems \\
\hline Estonia & 9000 & All levels & 2005 & 6 & None \\
\hline Geneva & 185526 & All levels & 2001 & 8 & None \\
\hline India & $770 \mathrm{~m}$ & State & 2001 & 4 & None \\
\hline Spain & 300000 & Municipal & 2002 & 1 & None \\
\hline Brazil & $140 \mathrm{~m}$ & All levels & 1996 & 4 & None \\
\hline Namibia & $1.2 \mathrm{~m}$ & National & 2014 & 1 & None \\
\hline Belgium & $3.2 \mathrm{~m}$ & $\begin{array}{c}\text { General \& } \\
\text { municipal }\end{array}$ & 1994 & 1 & Failed \\
\hline Ireland & $4.5 \mathrm{~m}$ & State & 2002 & 2 & Failed \\
\hline Australia & 218000 & ACT federal & 2001 & 1 & None \\
\hline Philippines & $52 \mathrm{~m}$ & State & 2010 & 1 & None \\
\hline UK & $1.5 \mathrm{~m}$ & Local govt & 2000 & 2 & None \\
\hline Canada & 98000 & Municipal & 2002 & 1 & None \\
\hline
\end{tabular}

Very few countries have endeavoured to implement m-voting and only one country Estonia [6], [14] has implemented partial $\mathrm{m}$-voting at a large 
scale. A vast number of countries has either piloted or implemented e-voting (fully or partially) but very few have been successful. Table 1 lists some of countries who have implemented e-voting.

\section{Methodology}

The primary objective for this study was to investigate factors that may have influence in the successful implementation of $\mathrm{m}$-voting in SA. A systematic review methodology was used for this study. The method is a procedure for collection and critical analyses of multiple research studies or papers. This research relied heavily on existing theory and research to identify the factors other researchers have investigated.

The main keywords used during the searching were restricted to: m-voting, e-voting, $\mathrm{m}$ government, e-government and m-participation. To capture as many relevant studies as possible, the electronic searches were performed using Google Scholar and other scientific journals and databases back to year 2000. Articles and studies that were most related to the research theme were considered for this study. Titles, abstracts and conclusions of conference papers and documents were reviewed and a total of 11 studies and papers were considered. The data in this study is presented narratively and statistically (meta-analysis).

\section{Findings}

A review of the literature revealed an insignificant number of research and studies investigating factors affecting the successful implementation of m-voting. However, most of the literature and research used for this study was adopted from other spheres including: e-voting, mgovernment, e-government and m-participation. Following are some of the studies on e-voting particularly in SA context:

In SA elections, ICTs have been employed in the electoral process, but not to the extent where it effectively assists during voter registration and voting. ICT can help protect the integrity of the elections especially during registration and identification of voters [4]. Bassey and Netshipise [4] believe this will go a long way to encourage transparency and trustworthiness of the voting system, and perhaps eradicate election frauds; multiple registrations, voting and impersonation. Their study proposed an improved electoral process for SA that aims at providing stronger security measures to protect and uphold its integrity.

Their proposed solution requires ICT tools to enhance both voter registration and identification processes on a real-time mode in order to guarantee that a person registers or votes only once. They developed a prototype called VOTEX which makes use of biometric technology and secured wireless network. To promote and protects the integrity of SA elections, a new approach that is more transparent, trustworthy, accurate and reusable is indispensable [4].

Thakur, Olugbara, Millham, Wesso and Sharif [5] proposed and developed a mobile voting model that uses common-off-the shelf (COTS) mobile phones, in conjunction with a Near Field Communication (NFC) tag technology and a pragmatic biometric verification scheme. The $\mathrm{m}$ voting application being proposed leverages the auto-coupling capability of NFC, which also stores baseline information about voters. The auto-coupling feature mediates device familiarity requirement, which is a limiting factor for using mobile phones to administer elections satisfying transparency and ease of use. The baseline information stored in the NFC tag provides local biometric reference data that mediate intensive bandwidth consumption, computational requirement, provide for match-on-acard features and satisfy the constraint that only the eligible voter may vote.

Achieng's [3] study determined the factors that could influence the adoption and diffusion of evoting technologies within the SA context. The study explored the challenges of the current electoral process, and determined the factors that could influence the adoption and diffusion of e-voting technologies within the SA context. The findings also reveal that factors such as availability of ICT infrastructure and resources, digital divide, trust in technology, awareness of the technology and environment could influence the adoption process.

Table 2. Summary of factors affecting M-voting derived from literature

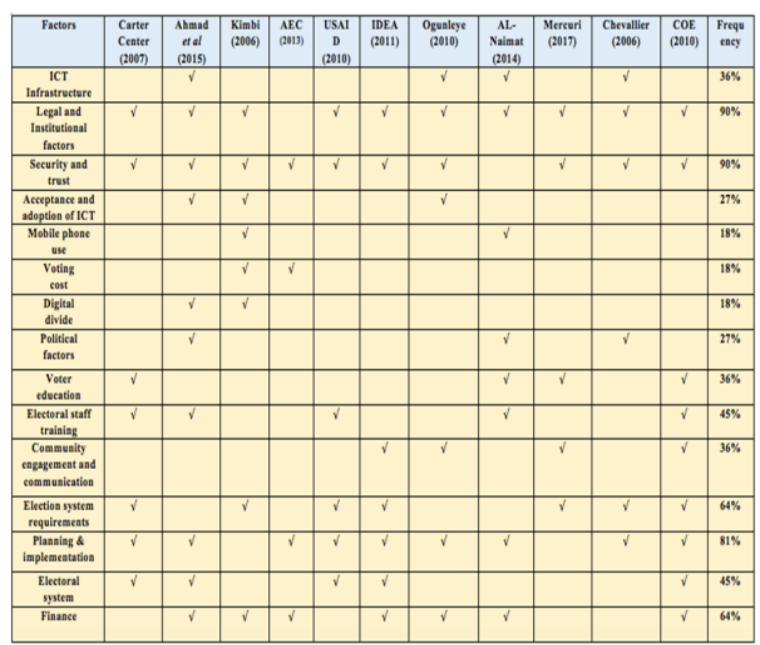

A long list of factors affecting the successful implementation of $\mathrm{m}$-voting were determined. In order to reduce these initial factors, the study merged any duplicate factors based on their meaning. At the 
end of this process, the study identified fifteen (15) factors that may affect m-voting implementation (see Table 2).

\section{Discussion}

The transformation from a traditional voting method to the use of an electronic voting system is not an easy exercise. The switch requires careful planning, and an environment in which the country's citizens are completely trusting of the technology and the electoral system itself. The International IDEA notes that it is essential that a strong trust of the electoral system exists, both at the socio-political level, operational and technical level [21], [22], [24]. The organisation recommends that countries should be clear on their goals and the purpose for using EVMs, and that thoughtful efforts must be made to ensure timely implementation, training, transparency, and sustainability [18], [19], [22].

M-voting implementation is an intricate phenomenon that involves organisational, technological, social and political issues [2], [12]. This study proposes a set of 15 factors which may affect the successful implementation of m-voting in SA. As indicated in Table 2 above, the study found that legal and institutional factors, as well as security and trust were more frequently recognised as the most critical factors by researchers. In addition, proper planning and implementation was the second in line of the critical factors, followed by finance and election system requirements. The electoral system and the electoral staff training were next and followed by voter education and community engagement and communication, then political factors and acceptance and adoption of ICT. Digital divide, mobile phone use and voting cost had a low ranking of importance compared to other factors. The explanation of each factor is described below.

\subsection{ICT Infrastructure}

ICT infrastructure is a major requirement that serves as the backbone of m-voting. ICT infrastructure includes recent IT infrastructure and telecommunication infrastructure that might be used for voting purpose. This infrastructure should be easily and always available for all citizens to use [1], [5], [12], [14].

\subsection{Legal and Institutional factors}

E-voting should be defined in the legal framework. The legal framework should lay the foundation for the use of e-voting for ensuring that fundamental human rights are fulfilled through their use. Amendments to the legal framework should include: physical and procedural aspects of voting and/or counting processes; voter identification; data security and retention testing and certification; audit mechanisms and conduct; transparency mechanisms and access to source code [4], [12], [14].

\subsection{Security and trust}

E-voting presents a host of security challenges. The security of e-voting systems is essential in order to ensure public confidence and overall electoral integrity. High security and authentication will give confidence to all the users of the system. Transparency, openness and constant interaction with stakeholders will increase trust, which can positively affect the implementation of e-voting [6], [12], [14], [23].

\subsection{Election system}

Whether the e-voting system is developed from scratch or bought, all stakeholders must be part of the process and must be satisfied with the chosen system. The chosen e-voting system should be able to satisfy all system requirements that are currently being offered by the paper-based system [2], [6], [15], [19], [22].

\subsection{Acceptance and adoption of ICT}

ICT is an umbrella term that includes any communication device or application, encompassing: radio, television, cellular phones, computer and network hardware and software, satellite systems and so on, as well as the various services and applications associated with them. There must be a certain level of acceptance and adoption of ICT innovations in order to be certain that $\mathrm{m}$-voting will be accepted and adopted by stakeholders [2], [10], [23].

\subsection{Mobile phone use}

Mobile phones have become a necessity in the daily life of people all over the globe, including the developing world. The level of mobile phone penetration will help determine mobile phone use in order to be certain that m-voting is not for few but for all even in the rural areas [1], [2], [5].

\subsection{Voting cost}

Paper-based voting is free to all voters, hence mvoting should also be free. Currently the use of a mobile phone or mobile phone networks cost mobile phone users. Solutions to provide m-voting for free should be developed [2], [22]. 


\subsection{Digital divide}

Digital divide is defined as inequalities in access to the Internet and resources for successful implementation of $\mathrm{m}$-voting. The digital divide gap should be determined and be closed or at least narrowed before the implementation of e-voting [4], [10], [18], [23].

\subsection{Political factors}

Political consensus is defined as the agreement of politicians, government and electoral officials on the importance of m-voting. Political consensus regarding the importance of e-voting has a huge influence on the success of m-voting implementation [20], [32].

\subsection{Voter education}

Voter education is necessary to ensure an informed community is able to effectively exercise its right to vote. Voter education campaigns and public awareness on m-voting are critical to the exercise of fundamental rights and the success of the m-voting project. Voter education should be accessible to all voters, including those with special needs [18], [21].

\subsection{Electoral staff training}

Electoral staff training is vital that all electoral staff be trained on m-voting and the system itself to be able to administer elections with the new technology. The staff should also be trained on IT skills to be able to adopt the new system [12], [22].

\subsection{Community engagement and communication}

Interaction with all stakeholders is also extremely vital, from the very beginning. This includes constant consultations and discussions with all stakeholders including political parties and civil society [14], [15], [20].

\subsection{Finance}

A proper budget is also considered an important factor to m-voting implementation. Although mvoting implementation may require a huge amount of money during the first year of implementation; this should be different as the years goes by. The budget must be discussed and agreed upon by all stakeholders before the implementation start [14], [16].

\subsection{Project planning and implementation}

The successful implementation of any project relies on proper planning and implementation of the plan, as well as effective leadership. These play a major role to the success of m-voting. Effective and strong leaders must control and support the projects at all phases of m-voting and must possess a clear plan and vision for the implementation of m-voting [12], [15].

\subsection{Electoral system}

Electoral administration is central to the success of any election, with electoral administrators playing a critical role in interpreting the electoral law, implementing electoral procedures, educating the electorate and procurement of the m-voting system [6], [15].

This study attempts to capture the essence of key factors for the successful implementation of $\mathrm{m}$ voting. Understanding these factors is critical for the progression of the field in both academia and practice. This study heavily relied on prior researches that have been done in the area and fifteen factors were identified as crucial for successful implementation of $\mathrm{m}$-voting. This provides a strong foundation for further research in m-voting implementation. All of these identified factors are important to be aware of and should also be managed in order to ensure the success of all other mgovernment initiatives.

\section{Conclusion}

Electronic voting systems offer more advantages compared to paper-based voting systems. Many other countries have made attempts to replace the traditional paper-based voting system with modern voting technology. Research indicates that most of these developments and transitions have failed and very few of them have been successful. The main aim of this study was to investigate factors that may have influence in the successful implementation of $\mathrm{m}$-voting in SA.

Successful implementation of m-voting in any given context is not only about the voting system itself and is not straightforward and simple as it seems. Projects encounter diverse problems whether in developed or developing countries. Many studies have focused on failed e-voting implementation, while very little focus on the factors leading to success. There are many factors that can affect the successful implementation of m-voting which includes technical, social, economic, organisational, and political factors. A country's technological progression, ICT infrastructure, voters m-readiness status, security, trust and transparency play a highly crucial role in the proliferation of $\mathrm{m}$-voting and $\mathrm{m}$ - 
government. The field of m-voting is moderately new and presents a variety of diverse research opportunities.

\section{Recommendations and Further Work}

This paper identified fifteen m-voting factors that have a potential to influence the successful implementation of $\mathrm{m}$-voting in SA. The factors were identified only from existing literature. The theories held by participants are the most crucial, but the most neglected sources of theory [25]. Hughes [26] suggests that these theories are important for two reasons. Firstly, these theories are real phenomena; they inform the participants' actions, and any attempt to interpret or explain the participants' actions without taking account of their actual beliefs, values and theories is probably fruitless [26]. Secondly, the participants have far more experience with the things that are being studied; and they may have important insights into what is going on that a researcher might miss - if they fail to take the participant's theories seriously [27].

Future work has to consider the views and opinions of all stakeholders (voters, political parties, observers, electoral management bodies etc.). The researcher recommends focus groups and maybe questionnaires for the voters in order to excavate the views and opinions of all stakeholders on factors that may have influence in the successful implementation of $\mathrm{m}$-voting in SA.

\section{References}

[1] U. O. Ekong \& C. K. Ayo, "The Prospects of M-Voting Implementation In Nigeria", 3GSM \& Mobile Computing: An Emerging Growth Engine for National Development, 2007, 172-179.

[2] U. O. Ekong \& V. Ekong, "M-voting: a panacea for enhanced e-participation", Asian Journal of Information Technology, 2010, 9(2), 111-116.

[3] M. Achieng \& E. Ruhode, "The adoption and challenges of electronic voting technologies within the South African context", arXiv preprint arXiv:1312.2406, 2013.

[4] I. Bassey \& N. Netshipise, "Extending E-Democracy to Enhance Voter Registration and Identification: South Africa Elections Perspective".

[5] S. Thakur, O. O. Olugbara, R. Millham, H. W. Wesso \& M. Sharif, "Transforming voting paradigm - the shift from inline through online to mobile voting", In 2014 IEEE 6th International Conference on Adaptive Science \& Technology (ICAST), 2014, (pp. 1-7). IEEE.

[6] A. G. Tsahkna, "E-voting: lessons from Estonia", European View, 2013, 12(1), 59-66.
[7] M. Chevallier, M. Warynski \& A. Sandoz, "Success factors of Geneva's e-voting system", Electronic Journal of e-Government, 2006, 4(2), 55-62.

[8] A. Das, "Usability of electronic voting system in India and innovatory approach", International Journal of Applied Science and Engineering Research, 2015, 4(5), 633-642.

[9] E. Eilu, R. Baguma \& J. S. Pettersson, "M-voting in developing countries: Findings from Uganda", Commonwealth Governance Handbook, 2014, 15, 25-28.

[10] E. Eilu \& R. Baguma, "Bridging the User Experience Gap in Mobile Phone Voting in Developing Countries", Strengthening the Role of Information and Communication Technology in Development, 2012, 134.

[11] D. Gefen, G. M. Rose, M. Warkentin \& P. A. Pavlou, "Cultural diversity and trust in IT adoption: A comparison of potential e-voters in the USA and South Africa", Journal of Global Information Management, 2005, 13(1), 54.

[12] R. Goswami \& D. Sen, "Case Study on'Technology and Elections in the World's Largest Democracy", 2011, Available at SSRN 1883354

[13] R. Heacock, "Mobile Activism in African Elections: A Comparative Case Study", 2009, DigiActive Research Series.

[14] S. Heiberg, P. Laud \& J. Willemson, "The application of i-voting for estonian parliamentary elections of 2011", In International Conference on E-Voting and Identity, 2011 (pp. 208-223), Springer Berlin Heidelberg.

[15] B. Isong, N. Netshipise \& G. Dzawo, "A New Approach for Protecting Elections Integrity in South Africa", International Journal of Computer Applications, 2013, 62(20).

[16] M. Magomelo, M. P. Mavhemwa \& D. Ndumiyana, "Effectiveness of mobile voting as a supplementary method to ballot casting: Case of Bindura University of Science Education".

[17] D. Mpabanga \& G. Mokhawa, "Is e-voting a possibility for Botswana's 2014 general elections?", Pula: Botswana Journal of African Studies, 2015, 27(2), 362375.

[18] S. A. Adeshina \& A. Ojo, "Design imperatives for evoting as a sociotechnical system", In Electronics, Computer and Computation (ICECCO), 2014 11th International Conference on, 2014, (pp. 1-4), IEEE.

[19] D. O. Adewumi, E. A. Oluwatosin, M. A. Bashorun \& O. T. Arulogun, "Framework for Multilingual Mobile EVoting Service Infrastructure for Democratic Governance", 2011.

[20] T. Adeyinka \& G. Olasina, "Voters' Perception of the Adequacy and Suitability of e-Voting in the Nigeria Polity", Handbook of Research on E-Government in Emerging Economies: Adoption, E-Participation, and Legal Frameworks: Adoption, E-Participation, and Legal Frameworks, 2012, 123. 
[21] L. Algeo, "Citizen Inclusion for all: Enhancing South Africa's e-Government Strategy with an m-Government Framework" (Doctoral dissertation, University of Birmingham), 2012.

[22] N. Boulus-Rødje \& R. Laanggaardsvej, "Mapping the literature: Socio-cultural, organizational and technological dimensions of e-voting technologies". In Electronic voting, 2012, (pp. 227-241).

[23] O. M. Olaniyi, D. O. Adewumi, E. A. Oluwatosin, O. T. Arulogun \& M. A. Bashorun, "Framework for multilingual mobile e-voting service infrastructure for democratic governance", African Journal of Computing and ICT (Journal of IEEE Nigeria Computer Section), 2011, 4(3), 23-32.

[24] A. Prosser \& R. Krimmer, "The dimensions of electronic voting technology, law, politics and society", Electronic Voting in Europe Technology, Law, Politics and Society, 2004, 21-28.

[25] P.L. Berger \& H. Kellner, "Sociology reinterpreted: An essay on method and vocation", Anchor Books, 1981.

[26] D. Hughes, "Participant observation in health research. Researching health: Qualitative, quantitative and mixed methods", 2007, pp.92-111.

[27]. J. A. Maxwell, "Conceptual framework: What do you think is going on?" Qualitative research design: An interactive approach, 2005, pp.33-63. 